\title{
Flow Patterns in Carotid Webs: A Patient-Based Computational Fluid Dynamics Study
}

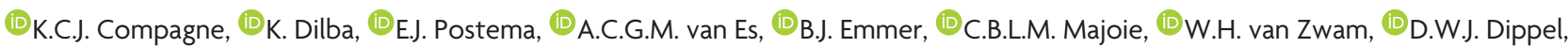 \\ (1).J. Wentzel, (1)A. van der Lugt, and (1)F.J.H. Gijsen, for the MR CLEAN investigators
}

\begin{abstract}
BACKGROUND AND PURPOSE: Carotid webs are increasingly recognized as an important cause of (recurrent) ischemic stroke in patients without other cardiovascular risk factors. Hemodynamic flow patterns induced by these lesions might be associated with thrombus formation. The aim of our study was to evaluate flow patterns of carotid webs using computational fluid dynamics.
\end{abstract}

MATERIALS AND METHODS: Patients with a carotid web in the Multicenter Randomized Clinical Trial of Endovascular Treatment of Acute Ischemic Stroke in the Netherlands (MR CLEAN) were selected for hemodynamic evaluation with computational fluid dynamics models based on lumen segmentations obtained from CT angiography scans. Hemodynamic parameters, including the area of recirculation zone, time-averaged wall shear stress, transverse wall shear stress, and the oscillatory shear index, were assessed and compared with the contralateral carotid bifurcation.

RESULTS: In our study, 9 patients were evaluated. Distal to the carotid webs, recirculation zones were significantly larger compared with the contralateral bifurcation (63 versus $43 \mathrm{~mm}^{2}, P=.02$ ). In the recirculation zones of the carotid webs and the contralateral carotid bifurcation, time-averaged wall shear stress values were comparable (both: median, $0.27 \mathrm{~Pa} ; P=.30$ ), while transverse wall shear stress and oscillatory shear index values were significantly higher in the recirculation zone of carotid webs (median, 0.25 versus $0.21 \mathrm{~Pa} ; P=.02$ and 0.39 versus $0.30 \mathrm{~Pa} ; P=.04$ ). At the minimal lumen area, simulations showed a significantly higher time-averaged wall shear stress in the web compared with the contralateral bifurcation (median, 0.58 versus $0.45 \mathrm{~Pa} ; P=.01$ ).

CONCLUSIONS: Carotid webs are associated with increased recirculation zones and regional increased wall shear stress metrics that are associated with disturbed flow. These findings suggest that a carotid web might stimulate thrombus formation, which increases the risk of acute ischemic stroke.

ABBREVIATIONS: CFD = computational fluid dynamics; IQR = interquartile range; OSI = oscillatory shear index; TAWSS = time-averaged wall shear stress; TransWSS $=$ transverse wall shear stress; WSS $=$ wall shear stress

C arotids webs are fibrous shelf-like lesions causing narrowing in the proximal internal carotid bulb. Although these lesions are rare, carotid webs are an important cause of (recurrent) ischemic stroke in patients without cardiovascular risk factors. ${ }^{1,2}$ Previous studies reported that carotid webs are more frequently observed in younger women and are associated with a high risk of

Received October 15, 2018; accepted after revision February 7, 2019

From the Departments of Radiology and Nuclear Medicine (K.C.J.C., K.D., A.C.G.M.v.E., A.v.d.L.), Neurology (K.C.J.C., D.W.J.D.), and Biomedical Engineering (K.D., E.J.P., J.J.W., F.J.H.G.), Erasmus MC, University Medical Center, Rotterdam, the Netherlands; Department of Radiology (B.J.E., C.B.L.M.M.), Amsterdam University Medical Center, University of Amsterdam, Amsterdam, the Netherlands; Depart ment of Radiology (W.H.v.Z.), Maastricht University Medical Center, Maastricht, the Netherlands; and Cardiovascular Research Institute Maastricht (W.H.v.Z.), Maastricht, the Netherlands.

The MR CLEAN trial was partly funded by the Dutch Heart Foundation and by unrestricted grants from Angiocare BV, Medtronic/Covidien/ev3, Medac Gmbh/ Lampero, Penumbra, Stryker, and Top Medical/Concentric.

MR CLEAN investigators are listed in the On-line Appendix. recurrent ischemic stroke. ${ }^{1,3}$ The underlying mechanism for the association between carotid webs and stroke is unknown, but it was speculated that the impact of the web morphology on flow patterns might lead to thrombus formation ${ }^{1}$; nonetheless, this speculation has never been studied.

Hemodynamic flow patterns have been extensively studied in atherosclerotic carotid arteries by computational fluid dynamics (CFD). ${ }^{4-7}$ This computer-based technique simulates fluid flow patterns based on the Navier-Stokes equations. By means of the image-based geometry of vessels, boundary conditions, and fluid properties, it is possible to simulate hemo-

Please address correspondence to F. Gijsen, PhD, Department of Bioengineering, Erasmus MC, University Medical Center, PO Box 20403000 CA Rotterdam, the Netherlands; e-mail f.gijsen@erasmusmc.nl

三 Indicates article with supplemental on-line appendix and table.

Indicates article with supplemental on-line photos.

http://dx.doi.org/10.3174/ajnr.A6012 
dynamic patterns. For example, areas of recirculation of blood flow can be investigated and quantified. These recirculation zones are observed in healthy carotid bifurcations but increase in size distal to a stenosis. ${ }^{8-13}$ In addition, frictional force induced by the blood flow (ie, wall shear stress [WSS]) can be investigated by CFD models. WSS affects many pathophysiologic processes related to atherosclerosis and is associated with ischemic stroke. ${ }^{4,14}$ Several WSS-derived parameters may be of interest in patients with webs. Time-averaged WSS (TAWSS) describes the wall shear stress magnitude over a cardiac cycle. Lower TAWSS values might stimulate atherosclerosis, while high values can cause endothelial trauma. ${ }^{4}$ Evaluating transverse WSS (TransWSS) can quantify multidirectional flows. ${ }^{15}$ TransWSS is the average of all WSS components perpendicular to the mean flow direction, consequently taking multidirectionality into account. This recently defined metric corresponds with the location of atherosclerotic lesions. ${ }^{16}$ Finally, the oscillatory shear index (OSI) can be assessed to characterize the temporal variability of WSS during a cardiac cycle. ${ }^{17}$ Larger changes in the direction of WSS during a cardiac cycle result in a higher OSI and are associated with atherogenesis. ${ }^{18}$

Both carotid webs and atherosclerotic stenosis are narrowing of the lumen at the level of the carotid bifurcation. However, the hemodynamic profiles may not be comparable due to differences in $3 \mathrm{D}$ morphology. In general, at the proximal part of both lesions, the lumen becomes gradually smaller. However, the lumen distal to the carotid webs differs from an atherosclerotic stenosis due to the shelf-like fibrous lesion, which may greatly influence the distal flow patterns. Gaining insight into the flow patterns of carotid webs might improve the understanding of the risk of (recurrent) ischemic stroke in patients with carotid webs.

In this study, we evaluated simulated flow patterns of carotid webs in patients with acute ischemic stroke with the use of patient-based CFD and compared these with the flow patterns in the contralateral carotid bifurcation.

\section{MATERIALS AND METHODS Patients and Imaging Data}

Patients were selected from the Multicenter Randomized Clinical Trial of Endovascular Treatment of Acute Ischemic Stroke in the Netherlands (MR CLEAN trial). ${ }^{19}$ Briefly, patients were included in the MR CLEAN trial $(n=500)$ if a proximal intracranial arterial occlusion was radiographically confirmed and had a minimum score of 2 on the NIHSS at baseline. The study protocol was approved by a central medical ethics committee and the research board of each participating center. Written informed consent before randomization was provided by all patients or their legal representatives. The MR CLEAN trial is registered under No. NTR1804 in the Dutch trial register and under ISRCTN10888758 in the International Standard Randomised Controlled Trial Number (ISRCTN) register.

Patients with a carotid web $(n=9)$ had a CTA scan with a slice increment of $0.5 \mathrm{~mm}$ and an average in-plane resolution of $0.46 \times$ $0.46 \mathrm{~mm}^{2}$. Stenosis measurements on CTA were semiautomatically performed by a cross-sectional area measurement at the level of the narrowest lumen divided by the disease-free area distal to the lesion.

\section{Segmentation and Meshing}

Semiautomated segmentations of both carotid arteries using a region-growing algorithm were performed with the open-source DICOM viewer Horos (Version 2.0.1). ${ }^{20}$ Due to different rates of contrast load in each CTA scan, the threshold intensity value was chosen for each patient on the basis of the best representation of morphology by 1 observer (K.C.J.C.). Vascular side branches and remaining calcifications were removed from the $3 \mathrm{D}$ volume-rendered lumen. The final segmentation included the common carotid artery, external carotid artery, and internal carotid artery. Flow extensions were added with a length of 3 diameters at the inlet and both outlets. Volumetric meshes of tetrahedral elements and prism layers were generated using ICEM CFD software, Version 17.1 (ANSYS, Canonsburg, Pennsylvania). The number of elements ranged between $2.45 \times 10^{6}$ and $7.80 \times 10^{6}$, with a minimal and maximal element size of 0.05 and $0.15 \mathrm{~mm}$, respectively.

\section{Computational Fluid Dynamics and Analysis}

A plug-like inflow profile was chosen. The average inlet velocity was calculated as a function of the diameter to obtain a wall shear stress of 1.2 Pa at the inlet flow extension..$^{21}$ Due to the absence of patient-specific boundary conditions and because no $(>50 \%)$ stenosis was present, the outflow ratios for the internal carotid artery/common carotid artery and external carotid artery/common carotid artery were assumed to be, respectively, 0.65 and 0.35 . $^{22}$ Blood was modeled as an incompressible fluid with a density of $1.06 \mathrm{~g} / \mathrm{cm}^{3}$, and the Carreau model was applied to account for the non-Newtonian shear thinning behavior. ${ }^{23}$ Time-dependent simulations were performed using generic flow waveform shapes as proposed by Lee et al. ${ }^{24}$ Two cardiac cycles were included, with a time-step of 0.01 seconds. Because the first cycle potentially contains numeric artifacts, only the results of the second cycle were used for the analyses.

From the time-dependent simulations, we extracted various hemodynamic parameters: TAWSS, TransWSS, and OSI. 2DTAWSS maps were created and used to determine the region of reversed flow (recirculation zone). Subsequently, the total surface area (square millimeters) and length (millimeters) of the recirculation zone were computed. ${ }^{25}$ Furthermore, TAWSS was assessed at the minimal lumen area of the carotid web or stenosis and in the recirculation zone. Transverse WSS and OSI were both assessed in the recirculation zone (On-line Fig 1). Transverse WSS was introduced by Peiffer et $\mathrm{al}^{15}$ as follows:

$$
\text { TransWSS }=\frac{1}{T} \int_{0}^{\mathrm{T}}\left|\vec{\tau}_{\omega}\left(\vec{n} \frac{\int_{0}^{\mathrm{T}} \vec{\tau}_{\omega} d t}{\left|\int_{0}^{\mathrm{T}} \vec{\tau}_{\omega} d t\right|}\right)\right| d t
$$

where $\vec{n}$ represents the normal-to-arterial surface.

For illustration, streamlines were created on the basis of the time-average velocity field. All CFD simulations were performed within Fluent 17.1 (ANSYS) using standard numeric techniques.

\section{Statistical Analysis}

Descriptive statistics of the characteristics of flow patterns are presented as medians and interquartile ranges (IQR) due to a non-normal distribution. Hemodynamic parameters of flow patterns in carotid bifurcations with a web were compared with the 
Table 1: Baseline characteristics of included patients

\begin{tabular}{|c|c|c|c|c|c|c|c|c|}
\hline Pt. & $\begin{array}{c}\text { Sex, } \\
\text { Age (yr) }\end{array}$ & $\begin{array}{l}\text { Carotid Web in } \\
\text { Symptomatic } \\
\text { Bifurcation }\end{array}$ & $\begin{array}{l}\text { Location } \\
\text { Intracranial } \\
\text { Occlusion }\end{array}$ & $\begin{array}{c}\text { Previous } \\
\text { Stroke }\end{array}$ & Smoking & Diabetes & $\begin{array}{c}\text { Atrial } \\
\text { Fibrillation }\end{array}$ & $\begin{array}{l}\text { Myocardial } \\
\text { Infarction }\end{array}$ \\
\hline 1 & $F, 45$ & Yes & Ml right & Yes & No & No & No & No \\
\hline 2 & M, 77 & Yes & M1 right & No & No & No & Yes & No \\
\hline 3 & $F, 67$ & Yes & M1 right & No & No & No & No & No \\
\hline 4 & $\mathrm{~F}, 44$ & Yes & ICA-T right & No & No & No & No & No \\
\hline 5 & $F, 66$ & Yes & M2 right & No & No & No & No & No \\
\hline 6 & $\mathrm{~F}, 45$ & Yes & ICA-T right & No & No & No & No & No \\
\hline 7 & $\mathrm{~F}, 59$ & Yes & Ml right & No & No & No & No & No \\
\hline 8 & $\mathrm{~F}, 46$ & Yes & M1 right & No & No & No & No & No \\
\hline 9 & $\mathrm{~F}, 73$ & No & M1 left & No & No & No & No & No \\
\hline
\end{tabular}

Note:-Pt. indicates patient; ICA-T, ICA terminus.
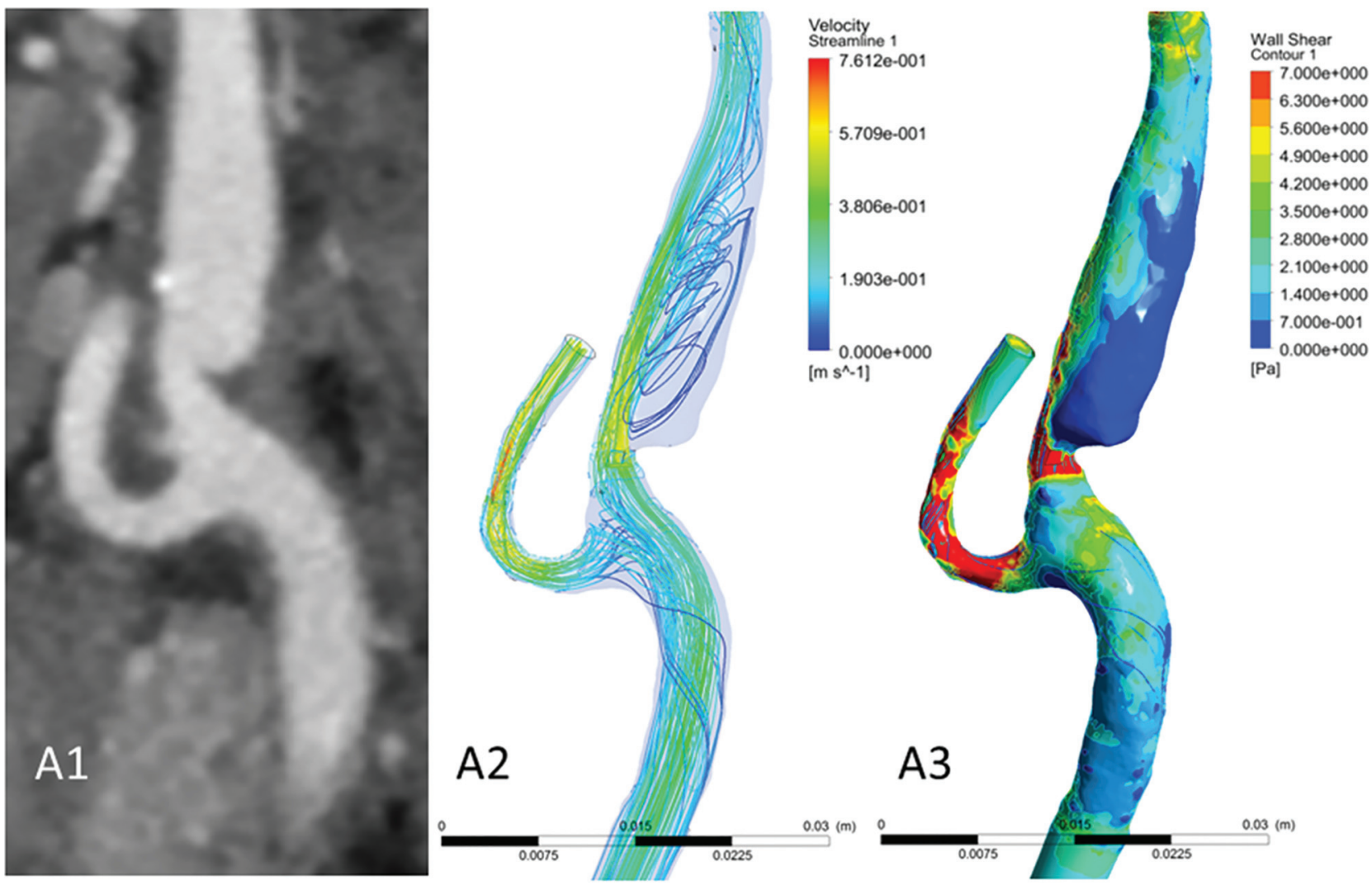

FIG 1. A case with a carotid web in the ipsilateral carotid bifurcation of a patient with ischemic stroke. Images of CTA (A7) and CFD simulations (A2, streamlines; $A 3$, wall shear stress). Focused on the region distal from the carotid web, a large recirculation zone is observed with low time-averaged WSS values. At the minimal lumen area at the location of the web, a high TAWSS is observed. Streamlines were based on the time-averaged velocity field.

contralateral carotid bifurcation (control group) in patients and evaluated with a paired Wilcoxon signed rank test. The degree of stenosis was correlated with the length of the recirculation zone using a Spearman rank correlation test. Statistical analyses were performed using R Studio (Version 3.4.2; http://rstudio.org/ download/desktop) and $\mathrm{R}$ packages haven, Hmisc, foreign, ggpaired, and ggpubr.

\section{RESULTS}

Included patients were mostly women $(n=8[89 \%])$ with a median age of 59 years (IQR, 45-70 years). All patients had a carotid web in the symptomatic carotid bifurcation of acute ischemic stroke, except for 1 patient in whom the carotid web was located in the asymptomatic carotid bifurcation. One patient had a history of atrial fibrillation (Table 1).

A representative case of a carotid artery web is shown in Fig 1. The streamlines show that in the region distal from the carotid web, a large recirculation zone is observed. Furthermore, at the minimal lumen area at the location of the web, a high TAWSS is observed.

The results of the CFD simulation of the carotid bifurcations are summarized in Table 2 and On-line Fig 2. The severity of the stenosis caused by the web varied from $13 \%$ to $70 \%$. At the contralateral carotid bifurcation, stenoses were observed in 3 patients (range, 14\%-56\%). In both carotid arteries with webs as well as in the contralateral carotid arteries, recirculation zones were ob- 


\begin{tabular}{ll}
\hline Recirculation zone & \\
Area (median) (IQR) $\left(\mathrm{mm}^{2}\right)$ & $63.61(50.60-99.38)$ \\
Length (median) (IQR) (mm) & $6.90(5.60-8.60)$ \\
Mean TAWSS (median) (IQR) (Pa) & $0.27(0.23-0.34)$ \\
Maximum TransWSS (median) (IQR) (Pa) & $0.25(0.20-0.31)$ \\
Maximum OSI (median) (IQR) & $0.39(0.36-0.43)$ \\
At level of minimum lumen area & \\
Maximum TAWSS (median) (IQR) (Pa) & $0.58(0.51-0.61)$
\end{tabular}

$43.0(36.46-50.34)$
$1.80(1.40-2.10)$
$0.27(0.22-0.28)$
$0.21(0.10-0.23)$
$0.30(0.19-0.33)$

a $P$ values were obtained from a paired Wilcoxon signed rank test.

served. However, total surface and length of the recirculation zone were significantly larger in a carotid bifurcation with a web compared with the contralateral carotid bifurcation (mean withinpatient differences, $38 \mathrm{~mm}^{2}$ and $6 \mathrm{~mm}$, respectively) (Table 2 and Fig 2A). This difference was present in all patients except the patient who had a web in the asymptomatic carotid bifurcation (Online Table). TAWSS in the recirculation zones of carotid bifurcations with webs and in the contralateral carotid bifurcation did not significantly differ. Maximum TransWSS values were significantly higher in the recirculation zones distal to the carotid web (mean within-patient difference, 0.09 Pa; 87\%) (Fig 2B). Likewise, OSI values were significantly higher in the recirculation zones in the carotid bifurcations with webs (mean within-patient difference, $0.12 ; 55 \%$ ) (Fig 2C). At the minimal lumen area at the location of the carotid web, simulations showed a significantly higher maximum TAWSS compared with the contralateral bifurcation (mean within-patient difference, 0.20 Pa; 44\%) (Fig 2D).

In the carotid bifurcations with a web, no correlation between the degree of stenosis and the surface or length of the recirculation zone was observed ( $\rho=0.23, P=.55$ and $\rho=0.27, P=.49$, respectively).

\section{DISCUSSION}

This study provided insight into the flow patterns associated with carotid webs in the carotid bifurcation. We observed that carotid webs show increased recirculation zones with corresponding higher OSI and TransWSS values compared with the contralateral carotid bifurcation in patients with acute ischemic stroke. Furthermore, at the minimal lumen area, higher maximum TAWSS values were observed in the carotid bifurcations with a web.

Recirculation of blood is associated with an increase in platelet deposition and aggregation, which could lead to thrombogenesis with time. ${ }^{26}$ All patients in our study had a larger total surface of recirculation in the bifurcation with a carotid web compared with the contralateral side, except in 1 patient who had a web in the asymptomatic carotid bifurcation. In our study, we did not find a significant association between the length or total surface of the recirculation zone and the degree of stenosis caused by a carotid web. It is possible that the degree of stenosis does not reflect the complex geometry distal from the stenosis, which is the main driver of the hemodynamic patterns.

We observed a high maximum TAWSS at the site of minimal lumen area caused by the carotid web. This finding has also been observed proximal to the minimal lumen area in patients with a stenosed artery due to atherosclerosis. ${ }^{4,21,27}$ In perspective, healthy individuals have an averaged WSS in the carotid arteries of approximately $1.2 \mathrm{~Pa}^{21}$ However, in recirculation zones, low
WSS is characteristically common. ${ }^{28}$ Vascular walls exposed to low WSS are prone to atherosclerosis and platelet aggregation, while high WSS induces platelet activation. ${ }^{4,29}$ Despite similar TAWSS values in the recirculation zones of carotid bifurcations with webs and their contralateral carotid bifurcations, higher TransWSS and OSI values in carotid bifurcations with a carotid web were observed. These observations represent a multidirectional disturbed blood flow, which might be prone to vascular wall dysfunction. ${ }^{30}$ Along with larger recirculation zones promoting platelet aggregation to the endothelium, shear-induced activated platelets might be more likely to adhere and cohere with each other, eventually leading to thrombus formation distal to the carotid web.

A limitation of our study is the small number of evaluated patients. This is partly due to the low prevalence of carotid webs. However, we also excluded 3 patients from CFD analysis due to poor $3 \mathrm{D}$ segmentation caused by insufficient imaging quality of the CTA scan. Thus, the statistical power of our analysis is limited, and results must be interpreted with care. Second, due to the retrospective study design, only data from CTA scans were available, resulting in missing patient-specific boundary conditions. Thus, in- and outlet properties were estimated and generalized for all our patients. ${ }^{22}$ None of our patients had a significant (>50\%) stenosis in both carotid arteries, suggesting that the assumed flow ratio between ICA/common carotid artery and external carotid artery/common carotid artery would be more reliable compared with estimations based on the Murray law. ${ }^{31}$ Further studies on flow patterns of carotid webs could overcome this problem by measuring blood flow with phase-contrast MR imaging scans. ${ }^{32}$ In addition, patient-specific waveforms can be determined instead of generic waveforms as in the current study. Furthermore, turbulence models were not considered in our study despite the presence of a stenosis caused by the carotid web. However, previous research has shown that flow instabilities might occur under these conditions, but turbulence is not expected to occur. ${ }^{33}$

Recent studies have shown that carotid webs might be associated with acute ischemic stroke in younger patients without cardiovascular risk factors. ${ }^{34-36}$ The results of the simulated flow patterns in the current study might be helpful in defining a therapeutic strategy for evaluation. Despite the use of antithrombotic agents, patients with a carotid web have a high risk of recurrent stroke. ${ }^{2,3}$ However, thrombus formation in a carotid web might be comparable with thrombus formation in the atrial appendage, which is currently treated with oral anticoagulants. ${ }^{37}$ Other potential treatment strategies of carotid webs are endovascular 


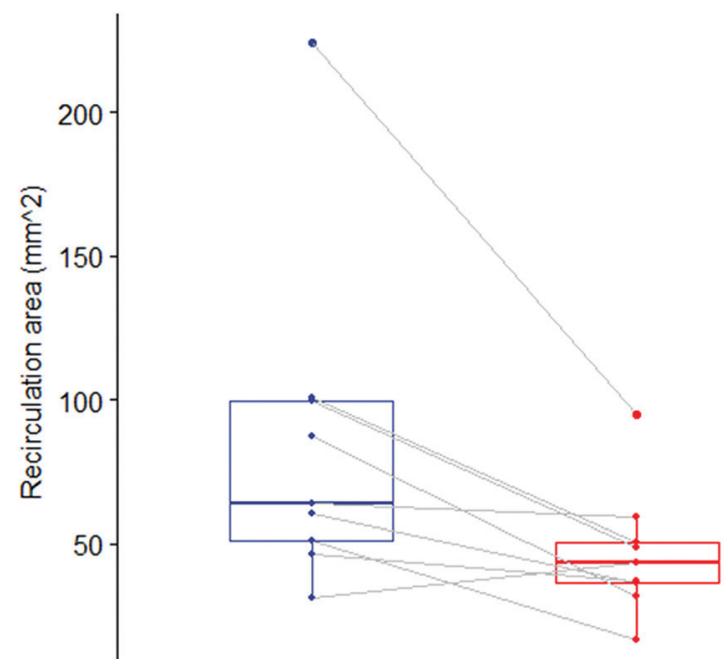

A

Web

Carotid bifurcation

legend

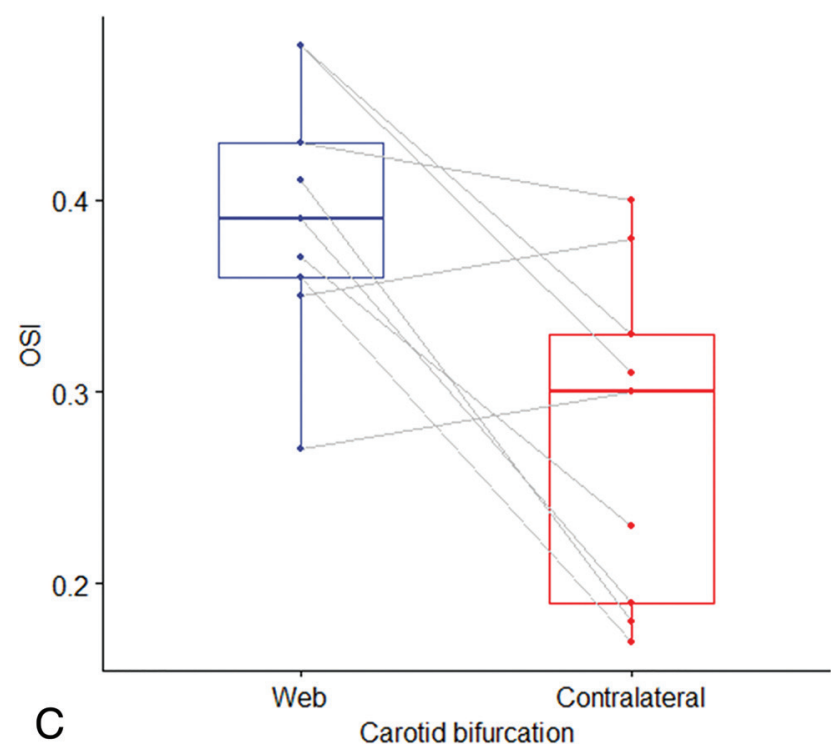

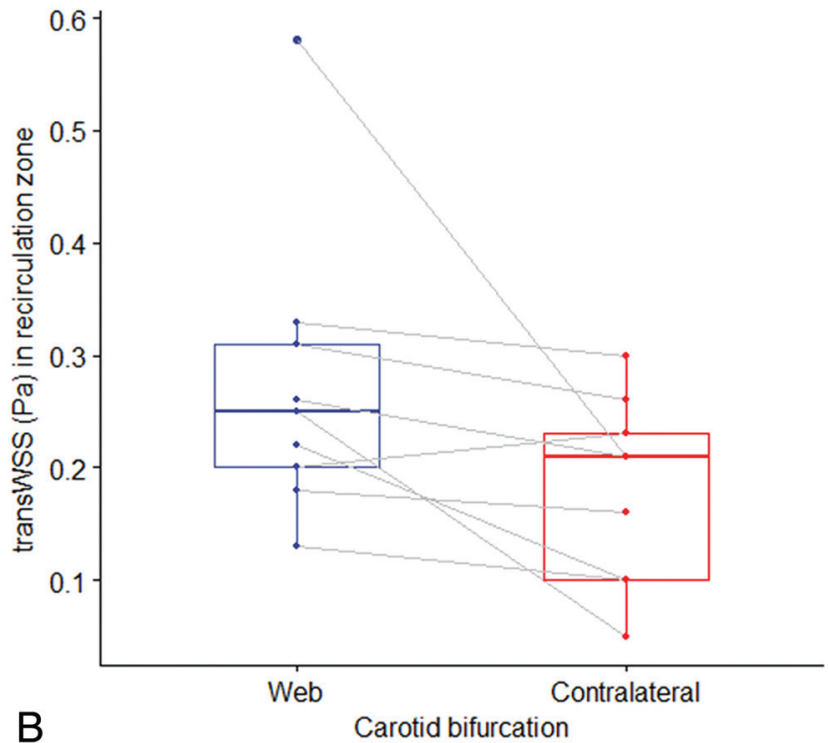

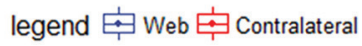

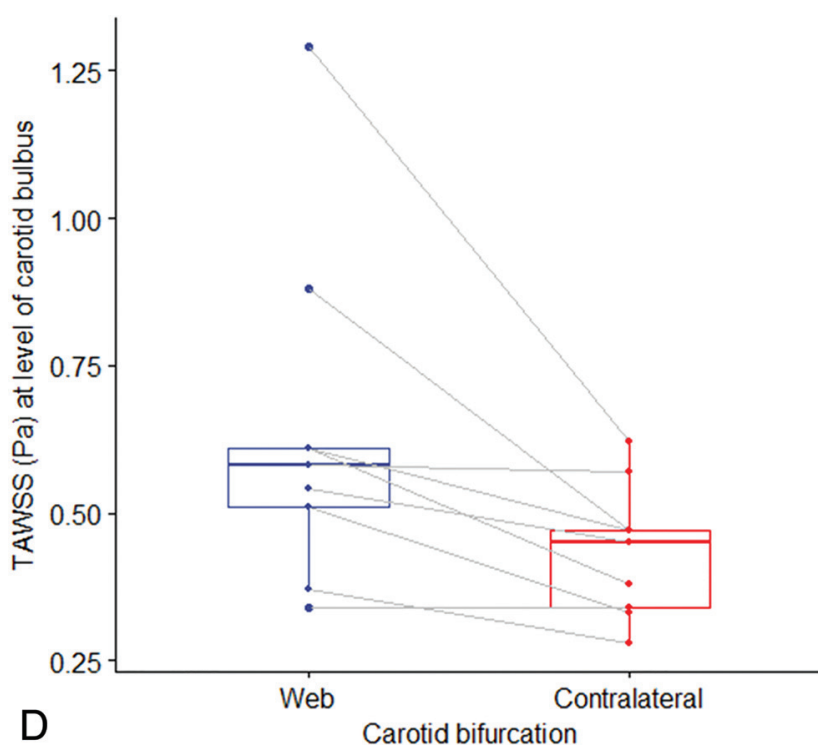

FIG 2. Boxplots showing the distribution of the total surface of the recirculation zone, TransWSS, OSI, and TAWSS for the carotid bifurcation with a web and the contralateral bifurcation. $P$ values were obtained from a paired Wilcoxon signed rank test. $A$, Distribution of the total surface of the recirculation area, which was statistically significant $(P=.02)$ larger in carotid bifurcations with a web compared with the contralateral carotid bifurcation (control group) within patients. $B$, Distribution of TransWSS in the recirculation zone, which was statistically significant $(P=$ .02) larger in carotid bifurcations with a web compared with the contralateral carotid bifurcation (control group) within patients. $C$, Distribution of maximum OSI in the recirculation zone, which was statistically significant $(P=.04)$ larger in carotid bifurcations with a web compared with the contralateral carotid bifurcation (control group) within patients. D, Distribution of maximum time-averaged wall shear stress (Pascal) at the level of the carotid bulb, which was statistically significant $(P=.01)$ larger in carotid bifurcations with a web compared with the contralateral carotid bifurcation (control group) within patients.

treatment (eg, carotid angioplasty or stent placement) or carotid endarterectomy. ${ }^{1,38,39}$

\section{CONCLUSIONS}

Carotid webs are associated with considerable recirculation zones and regional increased WSS. These findings suggest that a carotid web might stimulate thrombus formation, which increases the risk of acute ischemic stroke.
Disclosures: Diederik W.J. Dippel—UNRELATED: Grants/Grants Pending: Dutch Heart Foundation, Brain Foundation Netherlands, the Netherlands Organisation for Health Research and Development, Health Holland Top Sector Life Sciences and Health, Angiocare BV, Covidien/ev3, Penumbra, Medac Gmbh/Lampero, Top Medical/Concentric, Stryker, Stryker European Operations BV, Medtronic, Thrombolytic Science International.* Charles B.L.M. Majoie—RELATED: Grant: Twin Foundation*; UNRELATED: Grant: CVON/Dutch Heart Foundation, European Commission, Stryker*; OTHER RELATIONSHIPS: Shareholder Nico.lab (modest compensation), a company that focuses on the use of artificial intelligence for medical image analysis. Aad van der Lugt-RELATED: Grant: Dutch Heart Foundation, Angiocare BV, Medtronic/Covidien/ev3, Medac Gmbh/Lampero, Penumbra, Stryker, Top Medi- 
cal/Concentric, Comments: Erasmus University Medical Center received unrestricted grants for the MR CLEAN studies*; UNRELATED: Consultancy: Stryker, Comments: Erasmus University Medical Center Rotterdam received support for consultations*; Grants/Grants Pending: Stryker, Comments: Erasmus University Medical Center Rotterdam received a grant for conducting EVT studies. ${ }^{*}$ Wim $\mathrm{H}$. van Zwam-RELATED: Grant: Codman Neuro, Stryker*; UNRELATED: Grants/Grants Pending: the Netherlands Organisation for Health Research and Development.* *Money paid to the institution.

\section{REFERENCES}

1. Choi PM, Singh D, Trivedi A, et al. Carotid webs and recurrent ischemic strokes in the era of CT angiography. AJNR Am J Neuroradiol 2015;36:2134-39 CrossRef Medline

2. Joux J, Chausson N, Jeannin S, et al. Carotid-bulb atypical fibromuscular dysplasia in young Afro-Caribbean patients with stroke. Stroke 2014;45:3711-13 CrossRef Medline

3. Haussen DC, Grossberg JA, Bouslama M, et al. Carotid web (intimal fibromuscular dysplasia) has high stroke recurrence risk and is amenable to stenting. Stroke 2017;48:3134-37 CrossRef Medline

4. Malek AM, Alper SL, Izumo S. Hemodynamic shear stress and its role in atherosclerosis. JAMA 1999;282:2035-42 CrossRef Medline

5. Sui B, Gao P, Lin Y, et al. Blood flow pattern and wall shear stress in the internal carotid arteries of healthy subjects. Acta Radiol 2008;49: 806-14 CrossRef Medline

6. Perktold K, Resch M, Florian H. Pulsatile non-Newtonian flow characteristics in a three-dimensional human carotid bifurcation model. J Biomech Eng 1991;113:464-75 CrossRef Medline

7. Kamenskiy AV, Dzenis YA, Mactaggart JN, et al. In vivo three-dimensional blood velocity profile shapes in the human common, internal, and external carotid arteries. J Vasc Surg 2011;54:1011-20 CrossRef Medline

8. Cebral JR, Yim PJ, Löhner R, et al. Blood flow modeling in carotid arteries with computational fluid dynamics and MR imaging. Acad Radiol 2002;9:1286-99 CrossRef Medline

9. Lee SE, Lee SW, Fischer PF, et al. Direct numerical simulation of transitional flow in a stenosed carotid bifurcation. J Biomech 2008; 41:2551-61 CrossRef Medline

10. Stroud JS, Berger SA, Saloner D. Numerical analysis of flow through a severely stenotic carotid artery bifurcation. J Biomech Eng 2002; 124:9-20 CrossRef Medline

11. Steinman DA, Thomas JB, Ladak HM, et al. Reconstruction of carotid bifurcation hemodynamics and wall thickness using computational fluid dynamics and MRI. Magn Reson Med 2002;47:149-59 CrossRef Medline

12. Marshall I, Zhao S, Papathanasopoulou P, et al. MRI and CFD studies of pulsatile flow in healthy and stenosed carotid bifurcation models. J Biomech 2004;37:679-87 CrossRef Medline

13. Lancellotti RM, Vergara C, Valdettaro L, et al. Large eddy simulations for blood dynamics in realistic stenotic carotids. Int J Numer Method Biomed Eng 2017;33 CrossRef Medline

14. Carallo C, Lucca LF, Ciamei M, et al. Wall shear stress is lower in the carotid artery responsible for a unilateral ischemic stroke. Atherosclerosis 2006;185:108-13 CrossRef Medline

15. Peiffer V, Sherwin SJ, Weinberg PD. Computation in the rabbit aorta of a new metric, the transverse wall shear stress, to quantify the multidirectional character of disturbed blood flow. J Biomech 2013; 46:2651-58 CrossRef Medline

16. Mohamied Y, Sherwin SJ, Weinberg PD. Understanding the fluid mechanics behind transverse wall shear stress. J Biomech 2017;50: 102-09 CrossRef Medline

17. He $\mathrm{X}, \mathrm{Ku} \mathrm{DN}$. Pulsatile flow in the human left coronary artery bifurcation: average conditions. J Biomech Eng 1996;118:74-82 CrossRef Medline

18. Cheng C, Tempel D, van Haperen R, et al. Atherosclerotic lesion size and vulnerability are determined by patterns of fluid shear stress. Circulation 2006;113:2744-53 CrossRef Medline

19. Berkhemer OA, Fransen PS, Beumer D, et al. A randomized trial of intraarterial treatment for acute ischemic stroke. N Engl J Med 2015; 372:11-20 CrossRef Medline

20. Horos Project. DICOM image viewing and measuring. Horos. https://horosproject.org/about/. Accessed March 5, 2019

21. Cheng C, Helderman F, Tempel D, et al. Large variations in absolute wall shear stress levels within one species and between species. Atherosclerosis 2007;195:225-35 CrossRef Medline

22. Groen HC, Simons L, van den Bouwhuijsen QJ, et al. MRI-based quantification of outflow boundary conditions for computational fluid dynamics of stenosed human carotid arteries. J Biomech 2010; 43:2332-38 CrossRef Medline

23. Seo T, Schachter LG, Barakat AI. Computational study of fluid mechanical disturbance induced by endovascular stents. Ann Biomed Eng 2005;33:444-56 CrossRef Medline

24. Lee SW, Antiga L, Spence JD, et al. Geometry of the carotid bifurcation predicts its exposure to disturbed flow. Stroke 2008;39:2341-47 CrossRef Medline

25. Schrauwen JT, Karanasos A, van Ditzhuijzen NS, et al. Influence of the accuracy of angiography-based reconstructions on velocity and wall shear stress computations in coronary bifurcations: a phantom study. PLoS One 2015;10:e0145114 CrossRef Medline

26. Schoephoerster RT, Oynes F, Nunez G, et al. Effects of local geometry and fluid dynamics on regional platelet deposition on artificial surfaces. Arterioscler Thromb 1993;13:1806-13 CrossRef Medline

27. Slager CJ, Wentzel JJ, Gijsen FJ, et al. The role of shear stress in the destabilization of vulnerable plaques and related therapeutic implications. Nat Clin Pract Cardiovasc Med 2005;2:456-64 CrossRef Medline

28. Botnar R, Rappitsch G, Scheidegger MB, et al. Hemodynamics in the carotid artery bifurcation: a comparison between numerical simulations and in vitro MRI measurements. J Biomech 2000;33:137-44 CrossRef Medline

29. Chatzizisis YS, Coskun AU, Jonas M, et al. Role of endothelial shear stress in the natural history of coronary atherosclerosis and vascular remodeling: molecular, cellular, and vascular behavior. J Am Coll Cardiol 2007;49:2379-93 CrossRef Medline

30. Zhang Q, Gao B, Gu K, et al. The study on hemodynamic effect of varied support models of BJUT-II VAD on coronary artery: a primary CFD study. ASAIO J 2014;60:643-51 CrossRef Medline

31. Sherman TF. On connecting large vessels to small: the meaning of Murray's law. J Gen Physiol 1981;78:431-53 CrossRef Medline

32. von Schulthess GK, Higgins CB. Blood flow imaging with MR: spinphase phenomena. Radiology 1985;157:687-95 CrossRef Medline

33. Gijsen FJ, Palmen DE, van der Beek MH, et al. Analysis of the axial flow field in stenosed carotid artery bifurcation models: LDA experiments. J Biomech 1996;29:1483-89 CrossRef Medline

34. Compagne KC, van Es AC, Berkhemer OA, et al; MR CLEAN Trial Investigators. Prevalence of carotid web in patients with acute intracranial stroke due to intracranial large vessel occlusion. Radiology 2018;286:1000-07 CrossRef Medline

35. Pereira BJ, Batista UC, Tosello RT, et al. Web vessels: literature review and neurointerventional management. World Neurosurg 2018; 110:e907-16 CrossRef Medline

36. Coutinho JM, Derkatch S, Potvin AR, et al. Carotid artery web and ischemic stroke: a case-control study. Neurology 2017;88:65-69 CrossRef Medline

37. Kirchhof P, Benussi S, Kotecha D, et al. 2016 ESC guidelines for the management of atrial fibrillation developed in collaboration with EACTS. Rev Esp Cardiol (Engl Ed) 2017;70:50 CrossRef Medline

38. Elmokadem AH, Ansari SA, Sangha R, et al. Neurointerventional management of carotid webs associated with recurrent and acute cerebral ischemic syndromes. Interv Neuroradiol 2016;22:432-37 CrossRef Medline

39. Brinjikji W, Agid R, Pereira VM. Carotid stenting for treatment of symptomatic carotid webs: a single-center case series. Interv Neurol 2018;7:233-40 CrossRef Medline 